\title{
A Preliminary Evaluation of a School Support Program for Children with Autism Spectrum Disorders: Educator and School Level Outcomes and Program Processes
}

\author{
Janette McDougall, Michelle Servais, Katherine Meyer, Sheila Case, \\ Kara Dannenhold, Sue Johnson, and Colleen Riggin \\ Thames Valley Children's Centre
}

\begin{abstract}
This is a preliminary evaluation of a program aimed at providing training, consultation, and resource materials to educators in public schools in order to build the capacity of those educators and schools to meet the needs of students with autism spectrum disorders. Educator and school level outcomes were evaluated and information about program processes was gathered. One hundred and ninety-two educators completed study measures in the fall and spring of one school year. Educators receiving no services were compared on outcomes to educators who received services. Significant main effects of program condition in favour of beneficial effects of the program were found for two school level outcomes. On average, educators were satisfied with the program and found the various components of the service useful. Recommendations for future service delivery and research are discussed.
\end{abstract}

Over the last few decades there has been a major rise in the rate of autism (Rutter, 2005). This is due to a number of reasons, including a broadening of the conceptualization of autism as a spectrum disorder and the recognition that autism spectrum disorder (ASD) can co-occur in individuals with other disorders (Charman, Howlin, Berry, \& Prince, 2004). Increasing numbers of children are now diagnosed with ASD in the preschool years. Research has indicated that early and preschool intensive behavioural intervention based on the principles of applied behaviour analysis (ABA) is effective in teaching skills and reducing behaviour problems associated with ASD (e.g., LaRose \& Perry, 2006; Lovaas, 1987; McEachin, Smith, \& Lovaas, 1993; Perry, 2006). ABA is traditionally defined as the process of systematically applying interventions derived from the principles of behaviour to improve socially meaningful behaviours and to demonstrate that the interventions employed are responsible for the improvement in behaviour (Baer, Wolf, \& Risley, 1968). 
The rise in enrollment of children with ASD in public schools, and evidence of the success of early intensive behavioural intervention programs based on ABA principles, have brought a corresponding demand for these services to be provided in public school settings (Lerman, Vorndran, Addison, \& Contrucci-Kuhn, 2004). Consequently, many ABA based programs have emerged in public schools, with considerable variability among those programs (Steege, Mace, Perry, \& Longenecker, 2007).

Although ABA is often associated with intensive one-to-one programming and the use of systematic instruction (e.g., discrete trial teaching), a wide array of evidenced-based ABA interventions can potentially be used in school-based programs in both separate and regular classrooms, such as incidental teaching, task analysis, peer-mediated instruction, shaping, chaining, prompting, fading, and generalization (see Steege et al., 2007, for a brief overview of evidenced-based ABA intervention approaches used in school-based programs for students with ASD).

Public school boards are increasingly being asked to provide direct one-to-one intensive ABA treatment to students with ASD via specially trained therapists and/or to provide training, consultation, and resources to educators regarding ABA and other evidence-based behavioural teaching strategies to enable them to successfully incorporate such practices and strategies into the regular classroom (Grey, Honan, McClean, \& Daly, 2005; Jacobson, 2000). To date, few well-designed, controlled evaluations of interventions for students with ASD in public school settings have been conducted (Charman et al., 2004). Studies of school-based intensive, behavioural interventions for students with ASD are lacking (Eikeseth, Smith, Jahr, \& Eldevik, 2002). One exception is a study by Eikeseth and colleagues (2002) that suggests direct provision of intensive, behavioural ABA treatment in separate classrooms by trained special education therapists, with a gradual shift in focus to help students generalize skills to the regular classroom, can be successfully implemented in public schools and can lead to significant gains in cognitive, language, and adaptive skills for some students aged 4 to 7 with autism.

Moreover, few well-designed studies have evaluated the effectiveness of indirect services that provide training, consultation, and resources to educators who work with students with ASD in public school settings. Those studies that have been conducted suggest that such programs can serve to resolve educators' concerns and increase their competency related to working with students with autism in the regular classroom (Herron \& Buss, 1991). In addition, these types of services appear to have a positive impact on specific child outcomes, including observed behaviours associated with autism, cooperative play, and classroom behaviour (Ikeda, Tucker, \& Rankin, 2002). One study evaluated child outcomes for a comprehensive training program in ABA for 11 special education teachers (Grey et al., 2005). An average of $80 \%$ change in the frequency of occurrence of target behaviours, namely, aggression, non-compliance and specific educational skills, was noted. Parents and teachers reported beneficial effects for both children and the school environment.

Parents of children with ASD have reported that, whatever the educational provision, educators should have adequate autism-specific training (Jindal-Snape, Douglas, Topping, Kerr, \& Smith, 2005). Despite ABA being one of very few interventions used in schools that is evidence-based (Simpson, 2005), and the rise in the delivery of school-based programs for students with ASD, most educators still do not receive adequate training in ABA or any other evidencebased behavioural teaching strategies (Grey et al., 2005). Parents of students with ASD taught in public schools have reported the primary reasons for dissatisfaction with their children's educational programming are the lack of knowledge among educators of ASD and their children's 
corresponding needs, as well as the lack of commitment of school staff (Barnard, Prior, \& Potter, 2000). Experts argue that the supportiveness of the school environment, just as much as a specific pedagogy, can make a difference to both the learning and social integration of students with ASD (Harrison, 1998). Numerous studies of general student populations have indicated that the quality of schools can make a significant difference to students' progress (e.g., Rutter \& Maughan, 2002; Sellström \& Bremberg, 2006). An optimally supportive school environment for students with ASD has been said to include (a) valuing students with special needs; (b) readily available human, physical, and informational supports to students and educators; (c) teaming and collaboration among educators and relevant stakeholders; and (d) support for students through transition points (Fletcher-Campbell, 2003).

Further research is needed that examines the effectiveness of indirect school-based programs in public schools for increasing the capacity of educators and schools to meet the needs of students with ASD (Lerman et al., 2004). Studies examining program processes, including educators' satisfaction with these types of programs and the usefulness of various program components, are also required.

\section{Study Purpose}

In March of 2004, the Ministry of Children and Youth Services in Ontario, Canada announced the introduction of a program targeting school-aged children with ASD: the School Support Program-Autism Spectrum Disorder (SSP-ASD). This program provides indirect services to publicly funded school board staff to meet the needs of students with ASD. The primary purpose of this study was to conduct a preliminary evaluation of the program over one school year, as delivered by Thames Valley Children's Centre-a children's rehabilitation centre funded by the Ministry of Children and Youth Services to provide the SSP-ASD program to school boards in the southwest region of Ontario. Since the program had recently been implemented, this preliminary study focused on proximal outcomes (educator level and school level outcomes) and program processes, including educator satisfaction with services. Child level outcomes were not measured in this preliminary evaluation. Changes to more distal outcomes (child level outcomes) were not expected to emerge until the capacity of educators and schools to meet the needs of students with ASD had been developed.

\section{Program Description}

The SSP-ASD program draws upon a whole-school approach (Luiselli, Putnam, Handler, $\&$ Feinberg, 2005) to provide a framework for enhancing the capacity of educators and schools to meet the needs of students with ASD. Services are provided to educators at the board, school, and classroom level. ASD consultants employed by Thames Valley Children's Centre provide services. Consultants are required to have a university undergraduate degree in psychology, education, or a related field or a community college diploma in a related field. Demonstrated, broadbased knowledge of ASD, including extensive experience working with children or youth with ASD within a behavioural approach is also required.

The SSP-ASD program has four components: planning, training, consultation, and resource development and sharing. Planning activities can occur region-wide or at the board level. ASD consultants meet with board ASD team staff about the implementation of yearly plans. 
Training is delivered to educators in any position in the board. Sessions range from small group workshops at staff meetings or during lunch periods to large professional development day sessions that have focused on such topics as Positive Behaviour Supports (Jackson, 2004). Individual consultations may include collaboration and problem solving, development of goals, classroom observation, suggestions for and demonstrations of classroom strategies, suggestions for the physical layout of the classroom, and coaching. Classroom strategies demonstrated by consultants are based on the principles of ABA or other evidenced-based behavioural teaching strategies, such as providing a structured environment and classroom incentives, and using daily visual schedules and instructional sequences (McClannahan \& Krantz, 1994). Resource development and sharing includes the provision of literature on various topics related to ASD, information about community resources, or the development of new resources. Any one school may request and receive a combination of the components to meet educators' needs.

The primary aims of the SSP-ASD program are to enhance (a) the knowledge of school staff with respect to the characteristics of ASD, the principles and practices of ABA, and other evidence-based behavioural teaching strategies; and (b) the supportiveness of the school environment for meeting the needs of students with ASD.

\section{Study Objectives}

Study objectives were to measure the following prior to and after reception of SSP-ASD support services over the course of the 2005-2006 school year: (a) knowledge among school staff about characteristics of ASD, principles and practices of ABA, and other evidence-based behavioural teaching strategies and (b) supportiveness of the school environment for meeting the needs of students with ASD. The study also assessed educators' satisfaction with the consultation process; educators' overall satisfaction with the SSP-ASD program; and educators' and ASD consultants' perceptions of the usefulness of various components of the SSP-ASD program.

\section{Method}

\section{Study Design and Sample}

The study employed a nonequivalent, comparison group pretest-posttest quasiexperimental research design (Singleton, Straits, \& Straits, 1993). For ethical and service delivery reasons it was not possible to use random assignment. However, a naturally occurring comparison group was available that included those educators who completed the study (i.e., completed the pretest and posttest measures) but had not received any services from the SSPASD program (see Results section for a description of the experimental and comparison groups).

A nested, stratified sample of elementary educators was targeted for the study. In southwestern Ontario, 13 public school boards received the SSP-ASD program. A list of schools where students with ASD were enrolled was obtained for each school board. Approximately 10\% of schools from each board-ranging between 1 and 17 schools, depending on the size of the board-were randomly selected for inclusion in the study, up to a maximum of 60 schools. One principal, three classroom teachers, one resource teacher, and one educational assistant within each of the randomly selected schools were randomly selected from school staff lists for inclusion in the study. The targeted sample included 60 principals, 60 educational assistants, 60 
resource teachers, and 180 classroom teachers - a potential total sample size of 360 educators.

\section{Procedure}

Study investigators obtained school board approvals throughout the summer of 2005. In September of 2005, study investigators contacted principals of schools randomly selected from each board. If principals expressed an interest in receiving more information, study materials were delivered to them by the ASD consultants. Once written consent had been received from principals, ASD consultants then met with the educational assistants, the resource teachers, and classroom teachers randomly selected from each school to inform them about the study. If educators expressed an interest in receiving more information, study materials were given to them.

If the school staff randomly selected to participate chose not to take part in the study, other potential participants were randomly selected from school staff lists. Educators either returned pretest packages by mail by a predetermined date to the study research associate or ASD consultants picked up completed, sealed packages from schools. Completed pretest packages were collected by late fall in 2005 just as the SSP-ASD program began to provide services to schools.

In late May of 2006, packages containing both the posttest outcome measures and the satisfaction measures were mailed to the educators who had completed study pretest measures. Once again, educators either returned posttest packages by mail by a predetermined date to the research associate or ASD consultants picked up completed, sealed packages from schools.

\section{Measures}

Study measures were chosen based on their suitability for measuring study outcomes and the quality of their psychometric properties. Where fitting, the description of measures includes internal consistency coefficients (Chronbach's alpha) estimated from the pre- and posttest assessments for this study and intraclass correlations (ICC) for examining the stability of the measures between pretest and posttest.

The Autism Spectrum Disorder Knowledge Quiz for Educators (ASD-KQE) was designed specifically for this study by the study's research team and was used to assess educators' knowledge of ASD, ABA, and other evidence-based behavioural teaching strategies. A literature search did not identify a pre-existing questionnaire suitable for use in this study. Academic and clinical colleagues established content validity of the ASD-KQE through revisions. The ASD$\mathrm{KQE}$ was then pilot tested on a small number of teachers $(n=5)$ to assess readability and difficulty level. It includes 20 multiple-choice questions, including "A child with an ASD may not engage in social interaction because (choose the best answer)" and "Pivotal Response Training is (choose the best answer)."

The supportiveness of the school environment was measured using an adapted version of the Factors for a Supportive Learning Environment Profile (Proactive Information Services, Inc., 1998). Factors important to a supportive learning environment that accommodate the needs of all students - including those with special needs - are captured by this measure. Specifically, four adapted subscales measuring (a) philosophy into practice, (b) supports, (c) teaming and collaboration, and (d) transitions were used. Adaptation involved slight wording changes and omission of questions that were not suitable. Four response options include (1) not in evidence except in 
isolated instances, (2) sometimes in evidence, (3) generally in evidence, and (4) in evidence. The philosophy into practice subscale includes nine items, such as "There is awareness of and deliberate attention to implementing what is known as 'best practice' in the school and classroom" and "Differentiated instruction and curricular adaptations are used to personalize learning opportunities for students" (pre post-test $\alpha=.84-.85$, test-retest ICC $=.74$ ). The support subscale includes nine items, such as "Teachers have access to and are supported in their professional development related to special education" and "School administrators, teachers, and support staff accept and value students with exceptionalities" (pre post-test $\alpha=.84-.85$, test-retest ICC $=.65$ ). The teaming and collaboration subscale includes four items, such as "A student's team includes parents/caregivers, the student (as appropriate), educators, paraprofessionals, other professionals (as appropriate) who work together to plan, implement, and evaluate a student's program" and "There is a broad-based and collaborative team approach to programming for individual students" (pre post-test $\alpha=.81-.80$, test-retest ICC $=.62$ ). The transitions subscale includes three questions, such as "There is a process for seamless transition between pre-school and schoolbased services" and "Direct connections are made between the school and community supports, services, and recreational opportunities to facilitate a student's integration into the community" (pre post-test $\alpha=.81-.83$, test-retest ICC $=.55$ ).

Educators' perceptions of the consultation process were evaluated using the Consultant Evaluation Form (Hughes, Erchul, Yoon, Jackson, \& Henington, 1997), a measure used in other studies to measure teachers' perceptions of consultant effectiveness (Hughes, Hasbrouck, Serdahl, Heidgerken, \& McHaney, 2001). It includes 12 items rated on a 7-point rating scale, with higher ratings indicating more favourable evaluations (e.g., "The consultant offered useful information" and "The consultant helped me see problems in a new light;" $\alpha=.96$ ).

The Client Satisfaction Questionnaire (Larsen, Attkisson, Hargreaves, \& Nguyen, 1979) was used to measure educators' satisfaction with the SSP-ASD program. It is a standardized, widely used global measure of overall client satisfaction with services. The 8 -item measure is based on a 4-point Likert scale, ranging from (4) very high satisfaction to (1) complete dissatisfaction $(\alpha=.95)$. It includes items such as "To what extent has the program addressed your concerns?" and "In an overall, general sense, how satisfied are you with the services you received from the program?" In completing the CSQ, educators who received SSP-ASD services were asked two additional open-ended questions about the three things they liked most and least about services.

The Usefulness of SSP-ASD Services was developed for this study to collect information on the usefulness of various components of the program from educators and ASD consultants. ASD consultants identified the questionnaire components. Components related to professional training, individual consultation and support, and resource development were rated on a 4-point Likert scale, ranging from (1) not at all useful to (4) very useful. The Usefulness of SSP-ASD Services for ASD consultants also included an open-ended question that asked for any additional feedback they might have about the program.

\section{Data Analyses}

Descriptive analyses were conducted to describe the study sample on a number of characteristics as well as to obtain means and standard deviations for the process and satisfaction measures. Repeated measures analysis of covariance (ANCOVA) was performed on the data for study outcomes with the condition (experimental vs. comparison group) as the between-subjects 
factor or independent variable of interest and scores for the posttest as the within-subjects factor or dependent variable. The pretest score and the number of children with ASD the educator worked with were control variables. Compared to repeated measures ANOVA, repeated measures ANCOVA is capable of enhancing statistical power by adjusting program effects for sample pretest/posttest correlations and possible pre-existing group differences at baseline (Lipsey, 1990). It also permits the control of theoretically important variables related to the outcomes of interest resulting in significant reductions in error variance not associated with the program. Post-hoc comparisons were performed on the adjusted means (Games, 1990).

\section{Results}

\section{Sample Descriptive Results}

During the recruitment period, ASD consultants approached 360 educators from 60 schools belonging to 13 school boards to participate in the study (roughly equal numbers of educators from each school). A total of 295 of the original 360 educators targeted for inclusion in the study provided formal written consent to participate and completed pretest measures. A total of 56 schools from 12 school boards participated in the study. Twenty-one ASD consultants provided services to the 12 school boards throughout the study.

Of the 295 participants who completed pretest questionnaires, 60 did not return the posttest questionnaire: 10 participants did not return it because they were no longer available (i.e., had moved, were not working); 18 participants noted that they did not receive services and therefore chose not to return the posttest; and 32 participants chose not to return the survey for various reasons (e.g., no time, not interested). Another 43 participants returned posttest questionnaires, but had not completed them: 31 participants reported not completing the posttest because they had not received services and 12 participants gave no reason for not completing the posttest. In sum, a total of 192 participants completed and returned posttest questionnaires.

The 192 participants who completed both the pretest and posttest questionnaires did not differ largely from the 103 who completed the pretest only with respect to demographic and other characteristics (see Table 1). However, a few trends were noted. The group that completed the pretest only included fewer educators who had completed a French language questionnaire, fewer principals, and more teachers compared to the group who completed both pretest and posttest. In addition, there was a slight trend for those who completed the pretest only to be younger and have less experience as educators.

Of those who completed both pretest and posttest, 22\% were principals, $19 \%$ were resource teachers, $18 \%$ were educational assistants, and $41 \%$ were classroom teachers. Over threequarters of participants were female. The majority $(88 \%)$ was between 31 and 60 years old. Ninety-eight percent taught at schools where English was the primary language. Most (79\%) had been working as an educator for 7 or more years. Participants were relatively evenly dispersed with respect to the grade they taught. Half $(51 \%)$ had some certification in special education. The majority $(66 \%)$ had received $0-8$ hours of inservice training related to ASD prior to the study. Eighteen percent (excluding principals) did not work with a student with ASD, 50\% worked with 1 to 2 students with ASD, and 10\% worked with three or more students with ASD.

Of the 192 educators who completed the study, 70 reported receiving no contact with the SSP-ASD program, 45 had one to four contacts, and 77 had five or more contacts. 
Table 1

Characteristics of Participants who Completed Pretest Only Compared to those who Completed Pretest and Posttest

\begin{tabular}{|c|c|c|}
\hline Variables & $\begin{array}{l}\text { Respondents who } \\
\text { completed pretest } \\
\text { only }^{\mathrm{a}}\end{array}$ & $\begin{array}{l}\text { Respondents who } \\
\text { completed pretest and }_{\text {posttest }^{\mathrm{b}}}\end{array}$ \\
\hline \multicolumn{3}{|l|}{ Role } \\
\hline Principal & $14(13.6 \%)$ & $42(21.9 \%)$ \\
\hline Resource Teacher & $19(18.4 \%)$ & $36(18.8 \%)$ \\
\hline Classroom Teacher & $53(51.5 \%)$ & $79(41.1 \%)$ \\
\hline Educational Assistant & $17(16.5 \%)$ & $35(18.2 \%)$ \\
\hline \multicolumn{3}{|l|}{ Language of questionnaire } \\
\hline English & $86(83.5 \%)$ & $188(97.9 \%)$ \\
\hline French & $17(16.5 \%)$ & $4(2.1 \%)$ \\
\hline \multicolumn{3}{|l|}{ Gender } \\
\hline Female & $80(77.7 \%)$ & $151(78.6 \%)$ \\
\hline Male & $20(19.4 \%)$ & $54(17.7 \%)$ \\
\hline Missing & $1(1.0 \%)$ & $6(3.6 \%)$ \\
\hline \multicolumn{3}{|l|}{ Age } \\
\hline 20-30 years & $14(13.6 \%)$ & $20(10.4 \%)$ \\
\hline $31-40$ years & $36(35.0 \%)$ & $51(26.8 \%)$ \\
\hline $41-50$ years & $28(27.2 \%)$ & $63(32.8 \%)$ \\
\hline $51-60$ years & $22(21.4 \%)$ & $54(28.1 \%)$ \\
\hline 61 years or older & $1(1.0 \%)$ & $0(0 \%)$ \\
\hline Missing & $2(1.9 \%)$ & $4(2.1 \%)$ \\
\hline \multicolumn{3}{|c|}{ Years of experience as educator } \\
\hline $1-6$ years & $28(26.2 \%)$ & $37(19.3 \%)$ \\
\hline $7-12$ years & $22(21.4 \%)$ & $38(19.8 \%)$ \\
\hline $13-18$ years & $25(24.3 \%)$ & $44(22.9 \%)$ \\
\hline 19 or more years & $27(26.2 \%)$ & $70(36.5 \%)$ \\
\hline Missing & $1(1.0 \%)$ & $3(1.6 \%)$ \\
\hline \multicolumn{3}{|l|}{ Certified in special education } \\
\hline Yes & $48(46.6 \%)$ & $89(46.4 \%)$ \\
\hline No & $51(49.5 \%)$ & $97(50.5 \%)$ \\
\hline Missing & $4(3.9 \%)$ & $6(3.1 \%)$ \\
\hline \multicolumn{3}{|c|}{$\begin{array}{l}\text { Number of inservice training hours related to ASD } \\
\text { (received to date) }\end{array}$} \\
\hline 0 hours & $37(35.9 \%)$ & $66(34.4 \%)$ \\
\hline $1-8$ hours & $44(42.7 \%)$ & $82(42.7 \%)$ \\
\hline $9-16$ hours & $3(2.9 \%)$ & $14(7.3 \%)$ \\
\hline $17-24$ hours & $8(7.8 \%)$ & $4(2.1 \%)$ \\
\hline 25 or more hours & $8(7.8 \%)$ & $22(11.5 \%)$ \\
\hline Missing & $3(2.9 \%)$ & $4(2.1 \%)$ \\
\hline
\end{tabular}


Table 1 (Continued)

Characteristics of Participants who Completed Pretest Only Compared to those who Completed Pretest and Posttest

\begin{tabular}{|c|c|c|}
\hline Variables & $\begin{array}{l}\text { Respondents who } \\
\text { completed pretest } \\
\text { only }^{\mathrm{a}}\end{array}$ & $\begin{array}{l}\text { Respondents who } \\
\text { completed pretest and } \\
\text { posttest }^{\mathrm{b}}\end{array}$ \\
\hline \multicolumn{3}{|c|}{$\begin{array}{l}\text { Number of ASD students with whom participant teach- } \\
\text { es/works }(M=1.30, S D=1.21)\end{array}$} \\
\hline 0 students & $24(23.3 \%)$ & $34(17.7 \%)$ \\
\hline 1 student & $41(39.8 \%)$ & $62(32.3 \%)$ \\
\hline 2 students & $9(8.7 \%)$ & $34(17.7 \%)$ \\
\hline 3 students & $3(2.9 \%)$ & $8(4.2 \%)$ \\
\hline 4 students & $7(6.8 \%)$ & $5(2.6 \%)$ \\
\hline 5 or more students & $1(1.0 \%)$ & $6(3.1 \%)$ \\
\hline Not applicable (Principal) & $13(12.6 \%)$ & $40(20.8 \%)$ \\
\hline Missing & $5(4.9 \%)$ & $3(1.6 \%)$ \\
\hline \multicolumn{3}{|c|}{ Years of experience with ASD students in school setting } \\
\hline No experience & $11(10.7 \%)$ & $18(9.4 \%)$ \\
\hline Less than 1 year & $21(20.4 \%)$ & $43(22.4 \%)$ \\
\hline More than 1 year but less than 5 & $42(40.8 \%)$ & $82(42.7 \%)$ \\
\hline More than 5 years but less than 10 & $15(14.6 \%)$ & $28(14.6 \%)$ \\
\hline Over 10 years & $11(10.7 \%)$ & $18(9.4 \%)$ \\
\hline Missing & $3(2.9 \%)$ & $3(1.6 \%)$ \\
\hline \multicolumn{3}{|l|}{$\begin{array}{l}\text { Grade in which participant teaches/works } \\
(M=3.38, S D=3.06)\end{array}$} \\
\hline JK & $10(9.7 \%)$ & $19(9.9 \%)$ \\
\hline SK & $3(2.9 \%)$ & $5(2.6 \%)$ \\
\hline Grade 1 & $11(10.7 \%)$ & $29(15.1 \%)$ \\
\hline Grade 2 & $7(6.8 \%)$ & $13(6.8 \%)$ \\
\hline Grade 3 & $9(8.7 \%)$ & $18(9.4 \%)$ \\
\hline Grade 4 & $7(6.8 \%)$ & $13(6.8 \%)$ \\
\hline Grade 5 & $11(10.7 \%)$ & $17(8.9 \%)$ \\
\hline Grade 6 & $12(11.7 \%)$ & $7(3.6 \%)$ \\
\hline Grade 7 & $8(7.8 \%)$ & $7(3.6 \%)$ \\
\hline Grade 8 & $2(1.9 \%)$ & $2(1.0 \%)$ \\
\hline Self-contained & $7(6.8 \%)$ & $9(4.7 \%)$ \\
\hline Not Applicable (Principal) & $14(13.6 \%)$ & $41(21.4 \%)$ \\
\hline Missing & $2(1.9 \%)$ & $12(6.3 \%)$ \\
\hline
\end{tabular}

${ }^{\mathrm{a}} n=103,{ }^{\mathrm{b}} n=192$. 
The 70 educators who reported receiving no contact with the program acted as the naturally occurring comparison group for the study. Due to the substantial variation found in number of contacts with the program among those participants who had received services, it was decided to further examine the effect of condition or "program dose" when ANCOVA was performed on the data for study outcomes by comparing two experimental groups (one group who had five or more contacts with the program vs. one group who had one to four contacts) with the comparison group.

Contact with the program could have occurred either during one-to-one consultation sessions or at small, medium, or large group training sessions. The majority of participants (53\%) received both one-to-one consultation and group training. Thirty-eight percent of participants received consultation only and 9\% received group training only. Principals met with consultants more often (74\%) than they attended training sessions $(33 \%)$, whereas classroom teachers and support staff, as a group, tended to consult (50\%) and attend training sessions (45\%) equally as often. The various types of educators were fairly equally distributed with respect to the number of contacts with the program (see Table 2).

Table 3 presents school demographics as reported by principals at pretest. Fifty-five percent of the 56 schools in the study were located in towns and cities with populations of less than 49,000 and $45 \%$ were located in cities with populations of more than 50,000. The majority (57\%) of schools had between 251 and 500 students. All schools had at least one student with ASD, with $48 \%$ having 2 to 4 students with ASD, and $28 \%$ having five or more students with ASD.

\section{Baseline Equivalence and Study Attrition}

Prior to evaluating the influence of the SSP-ASD program on study outcomes, possible threats to validity arising from non-equivalence of participants at baseline and attrition between pre and posttest questionnaires were assessed. To assess these threats, a one-way ANOVA was conducted for each outcome measured at pretest with the program condition as the independent variable. A main effect of condition was judged to infer non-equivalence between groups, posing a threat to internal validity. A one-way ANOVA was conducted for each outcome with attrition (completion of pretest and posttest vs. completion of pretest only) entered as the independent variable. A main effect of attrition was judged to infer that those who completed all study measures across testing occasions differed from those who completed only the pretest, posing a threat to external validity.

Evidence was found of a statistically significant $(p \leq .05)$ main effect of condition for only two of five models involving the outcomes of philosophy in practice and transitions. As mentioned above, the analyses conducted to estimate condition effects controlled statistically for these initial differences at pretest.

As stated, 295 educators participated in the study; however, 103 did not return/complete the posttest questionnaire. Attrition analyses indicated that participants who completed the posttest for an outcome did not differ significantly $(p \leq .05)$ on any outcomes at pretest when compared to participants who completed the pretest only, indicating little threat to external validity of the sample due to attrition. 
Table 2

Number of Contacts with SSP-ASD Program by School Role

\begin{tabular}{lccccc}
\hline \multicolumn{7}{c}{ School Role } \\
\hline $\begin{array}{l}\text { Number of contacts with } \\
\text { SSP-ASD program }\end{array}$ & Principal & $\begin{array}{c}\text { Classroom } \\
\text { Teacher }\end{array}$ & $\begin{array}{c}\text { Educational } \\
\text { Assistant }\end{array}$ & $\begin{array}{c}\text { Resource } \\
\text { Teacher }\end{array}$ & Total \\
\hline No Contact & 10 & 36 & 10 & 14 & 70 \\
One to four contacts & 8 & 18 & 11 & 8 & 45 \\
Five or more contacts & 24 & 27 & 15 & 11 & 77 \\
Total & 42 & 81 & 36 & 33 & 192 \\
\hline
\end{tabular}

Table 3

School Demographics as Reported By Principals at Pretest

\begin{tabular}{ll}
\hline Variables & Survey Respondents \\
\hline Approximate population of city/town where school is located & \\
$\quad$ Less than 1000 & $8(14.3 \%)$ \\
$1,000-9,999$ & $6(10.7 \%)$ \\
$10,000-49,000$ & $17(30.4 \%)$ \\
$50,000-100,000$ & $5(8.9 \%)$ \\
$\quad$ More than 100,000 & $20(35.7 \%)$ \\
Approximate number of students in school & \\
$0-250$ students & $15(26.8 \%)$ \\
$251-500$ students & $32(57.1 \%)$ \\
$501-750$ students & $7(12.5 \%)$ \\
$751-1,000$ students & $2(3.6 \%)$ \\
Approximate number of students with ASD in principal's school & \\
1 student & $13(23.2 \%)$ \\
$2-4$ students & $27(48.2 \%)$ \\
$5-7$ students & $11(19.6 \%)$ \\
More than 7 students & $5(8.9 \%)$ \\
\hline
\end{tabular}

Note. $n=56$.

\section{Study Outcomes}

To test the ANCOVA assumption of equality of slopes across groups, preliminary analyses were done for each outcome at pretest. Non-significant interactions were found, allowing the ANCOVA analyses to proceed. Statistically significant main effects of program condition in favour of beneficial effects of the SSP-ASD program were found for two aspects of the school environment. Specifically, a significant effect of condition was found between the group who had one to four contacts with the SSP-ASD program and the group who had no contact at all with the program with respect to supports in the school for accommodating the needs of students, $F(2,165)=4.60, p<0.05$; participants who had one to four contacts reporting greater supports 
than the group who had no contact at all with the program (see Table 4). Also, a significant effect of condition was found between the group who had one to four contacts with the program and the group who had no contact with the program with respect to teaming and collaboration, $F(2$, $167)=6.24, p<0.01$; participants who had one to four contacts reported more teaming and collaboration than the group who had no contact with the program.

Table 4

Adjusted Means Post Hoc Comparisons by Condition for Study Outcomes

\begin{tabular}{|c|c|c|c|c|c|}
\hline \multirow[b]{2}{*}{ Outcome Variables } & \multicolumn{3}{|c|}{ School Staff } & \multirow[b]{2}{*}{$\begin{array}{c}\text { Post hoc } \\
\text { test }\end{array}$} & \multirow[b]{2}{*}{$F$} \\
\hline & $\begin{array}{c}\text { no contact } \\
\text { at all } \\
\text { a }\end{array}$ & $\begin{array}{c}1 \text { to } 4 \\
\text { contacts }^{b} \\
b\end{array}$ & $\begin{array}{c}5 \text { or more } \\
\text { contacts }^{\mathrm{c}} \\
\mathrm{C}\end{array}$ & & \\
\hline Knowledge of ASD & 11.77 & 11.88 & 11.83 & & $(2,184) n s$ \\
\hline SE-Philosophy in Practice & 30.43 & 30.92 & 30.42 & & $(2,155) \mathrm{ns}$ \\
\hline SE-Supports & 27.11 & 29.54 & 27.80 & $a-b^{* *}$ & $(2,165) 4.60^{*}$ \\
\hline SE-Teaming and Collaboration & 11.22 & 12.65 & 11.95 & $a-b^{* *}$ & $(2,167) 6.24^{* *}$ \\
\hline SE-Transition & 8.09 & 8.70 & 8.73 & & $(2,153) \mathrm{ns}$ \\
\hline
\end{tabular}

Note. $\mathrm{SE}=$ School Environment.

${ }^{\mathrm{a}} n=70$. ${ }^{\mathrm{b}} n=45 .{ }^{\mathrm{c}} n=77$.

${ }^{*} p \leq 0.05 .{ }^{* *} p \leq 0.01$.

\section{Satisfaction with the Consultation Process}

On a scale of 1 to 7 , with 7 representing greatest satisfaction with the consultation process, the mean score for educators $(n=74)$ on the Consultant Evaluation Form was $5.3(S D=$ 1.2). Seven percent scored 3 or below, indicating complete to mild dissatisfaction; $24 \%$ scored above 3 or below 5, indicating indifference to some satisfaction; and 69\% scored 5 or above, indicating that the majority of educators were mostly to very satisfied with the consultation process.

\section{Overall Satisfaction with the SSP-ASD Program}

On a scale from 1 to 4 , with 4 representing greatest satisfaction, the mean score reported on the Client Satisfaction Questionnaire by educators $(n=84)$ receiving services from the SSPASD program was $3.0(S D=0.70)$. Six percent scored 2 or below, indicating complete to mild dissatisfaction; $30 \%$ scored above 2 or below 3, indicating indifference to some satisfaction; and $64 \%$ scored 3 or above, indicating that the majority of educators were mostly to very satisfied with services overall. On open-ended questions, most positive comments made by educators about the program could be grouped under two key theme areas: (a) quality of emotional and informational supports from ASD consultants and (b) the collaborative nature of services. Negative comments were fewer in number. Access to consultants was identified most often as an aspect of service that could be improved upon. 


\section{Perceived Usefulness of Components of the SSP-ASD Program}

On a scale from 1 to 4 , with 4 representing greatest perceived usefulness of services, the mean scores on the individual items of the Usefulness of SSP-ASD Services ranged from 2.4 to 3.3 for educators (see Table 5) and from 2.2 to 3.2 for ASD consultants, indicating that, on average, both educators and consultants viewed the usefulness of the various components of the program to range from somewhat useful to moderately useful.

Table 5

Usefulness of Components of SSP-ASD Consultation Program

\begin{tabular}{|c|c|c|c|c|c|c|}
\hline \multirow[t]{2}{*}{$\begin{array}{l}\text { Items from the Usefulness of } \\
\text { Services Questionnaire }\end{array}$} & \multicolumn{3}{|c|}{ Educators } & \multicolumn{3}{|c|}{ ASD consultants } \\
\hline & $n$ & $M$ & $S D$ & $n$ & $M$ & $S D$ \\
\hline \multicolumn{7}{|l|}{ Professional development/training } \\
\hline Informal "Lunch and Learn" session & 22 & 2.95 & 0.79 & 16 & 2.56 & 0.96 \\
\hline Early dismissal day session & 26 & 2.92 & 0.85 & 17 & 2.47 & 1.12 \\
\hline Professional development day session & 30 & 3.30 & 0.79 & 17 & 3.00 & 1.32 \\
\hline Staff meeting & 30 & 2.83 & 0.87 & 17 & 3.18 & 0.79 \\
\hline \multicolumn{7}{|l|}{ Individual consultation and support } \\
\hline Planning and goal development & 64 & 2.94 & 0.83 & 17 & 3.00 & 1.17 \\
\hline Observation in classroom & 62 & 2.98 & 0.88 & 17 & 3.12 & 0.60 \\
\hline Collaboration and problem solving & 70 & 3.06 & 0.83 & 17 & 2.88 & 0.86 \\
\hline Practical strategies for the classroom & 68 & 2.96 & 0.87 & 17 & 2.56 & 1.21 \\
\hline $\begin{array}{l}\text { Suggestions for modifications to physical } \\
\text { environment }\end{array}$ & 62 & 2.73 & 0.83 & 17 & 2.59 & 0.94 \\
\hline Suggestions for accommodation & 67 & 2.94 & 0.78 & 17 & 2.35 & 1.12 \\
\hline Coaching & 53 & 2.85 & 0.89 & 17 & 2.59 & 1.46 \\
\hline \multicolumn{7}{|l|}{ Resource development } \\
\hline $\begin{array}{l}\text { Resource materials provided/developed } \\
\text { by ASD consultants for educators }\end{array}$ & 70 & 2.83 & 0.87 & 17 & 3.12 & 0.70 \\
\hline $\begin{array}{l}\text { Information provided about accessing } \\
\text { other professionals }\end{array}$ & 63 & 2.71 & 0.99 & 17 & 2.47 & 1.38 \\
\hline $\begin{array}{l}\text { Information about other services or } \\
\text { community agencies to access }\end{array}$ & 53 & 2.36 & 0.88 & 17 & 2.18 & 1.19 \\
\hline
\end{tabular}

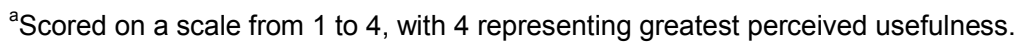

\section{Discussion}

Despite increased provision of indirect services for educators working with children with ASD in public schools, few efforts have been undertaken to evaluate the impact of these types of services on education systems. To address this shortfall, a preliminary evaluation of the Thames Valley Children's Centre SSP-ASD program over one school year was undertaken. 
Study findings suggest that the SSP-ASD program may be beginning to have a positive impact at the school level on publicly funded school boards in the southwest region of Ontario, Canada. Small beneficial program effects were found for two aspects of the supportiveness of the school learning environment for accommodating the needs of students: supports (e.g., availability of resource materials, access to professional development, staff valuing of students with special needs) and teaming and collaboration (e.g., collaborative team approach to programming for individual students, peer collaboration, and continuum of services). Interestingly, it was the group of educators who had been in contact with ASD consultants between one and four times that reported significantly more positive perceptions of available supports and teaming and collaboration than the group with no contact. It could be speculated that educators requiring more contacts may have had complex issues that the program had just begun to address. Support over a longer term may have been needed before beneficial effects could be realized for this group of educators. In addition, the reception of services over a longer period of time also may have been required for significant positive change to occur for other aspects of the school environment.

Study measures did not detect significant differences among groups with respect to staff knowledge of ASD, ABA, and other evidenced-based behavioural teaching strategies. This could be due to a number of factors, including measurement issues. The questionnaire used to measure educators' knowledge of ASD and ABA (i.e., the ASD-KQE) may not have been a good indicator of what type of information educators were actually absorbing from the program. The ASDKQE also seemed to be comprised of questions that were either too simple or too difficult.

Reception of services from other sources for the group who had no contact with the program may have also contributed to the lack of group differences for improving staff knowledge. Many school boards had existing ASD or special needs teams that might have worked with some of these participants over the school year. Still, other than the SSP-ASD program, only $8 \%$ of all participants reported having been enrolled in any other type of course or program related to ASD throughout the school year.

Lack of significant differences among groups for improving staff knowledge could also have been due to the SSP-ASD program having only recently been implemented. Uptake of knowledge of ASD, ABA, and other evidence-based behavioural teaching strategies by staff may be a more distal outcome that follows changes in the larger school environment for accommodating the needs of students.

Educators reported, on average, being mostly to highly satisfied with the consultation process and with the overall program. On open-ended questions, the most frequently reported positive aspects of service by educators were the quality of emotional and informational supports they received from the ASD consultants (e.g., staff were approachable, knowledgeable, flexible, personable; resources and recommendations were useful) and the collaborative nature of services (e.g., working as a team, personal contact, connection). Educators said consultants were "supportive rather than directive" and "kind, willing to listen, sympathized with how hard it is to work with and implement ideas." Consultants were said to recommend "customized activities that were made for my students" and it was thought that a "positive working relationship [was] built among all school team members." These qualitative comments are consistent with the quantitative findings, suggesting the program helps to foster a supportive learning environment. Consultants also commented positively about program implementation: "We have made gains over the past year in our boards. As a team I see we are beginning to have a better understanding of what our role is and what we can do." 
While a significant number of educators identified access to consultants as a positive aspect of service, those who offered suggestions for improvement of services most often reported wanting to meet with consultants more frequently, for longer periods of time, and/or at more convenient times. These suggestions are consistent with those made by educators in other evaluations of indirect services (Grey et al., 2005). One educator commented, "If only a supply came in so all team members could participate in discussions without interruptions." Others "wanted more flexibility" and stated that there was "not enough time to work one-on-one with [consultants]." Consultants also identified the amount of time spent with educators as an issue: "Release time for educators is still an issue for training and consultations, which doesn't allow our program to enhance knowledge or skills among educators as much as the program is capable of." Consultants also commented that "[educators] want direct support."

Limited professional development time and lack of funding for release time are key challenges that limit educator access to consultants (Lerman et al., 2004). Offering more lunchtime training sessions and sessions at other convenient times is one strategy that may enhance access. Working together with boards and schools to identify ways in which consultants can help to meet the needs of educators for professional development and for increased and convenient access to consultants following training sessions is an important area for program development. Strong leadership and "buy-in" at the board and school level are essential to support the effectiveness of the training and consultation components of the SSP-ASD program.

To ensure transfer of knowledge and, ultimately, skills it may be necessary to increase the amount of consultation time provided to educators. A time-limited restricted consultation process may not be sufficient particularly for teachers working with students who have high needs. Joyce and Showers (2002) advocate for a model of learning new skills, such as ABA and other evidence-based behavioural teaching strategies, that coincides with yet extends upon the components of the SSP-ASD program. They identify four key components of their learning model: (a) knowledge and exploring the theory or rationale for the new skills or strategies; (b) modeling the new skills (ideally in a setting closely approximate to the workplace); (c) practice of the skill over a period of 8 to 10 weeks; and (d) peer coaching.

Knowledge building, theory exploration, and modeling of ABA and other evidence-based behavioural teaching strategies all occur within the planning and training components of the SSP-ASD program. By providing training to all levels of educators, the SSP-ASD program provides the infrastructure for peer coaching or educators working collaboratively to effectively meet the needs of students with ASD. Within consultation lies the opportunity to support extended practice and coaching. Having ASD consultants in the role of educator coaches to support educators in "child-specific" situations (e.g., in the classroom and on the playground) for 8 to 10 weeks that educators need to practice strategies may be a cost-effective and practical model of service delivery. The cost of this additional time spent with educators may be outweighed by the educational and social benefits to the child, reduced costs in later years, and improvement in the school environment for educators and fellow students (Maurice, Green, \& Luce, 1996).

Indeed, what may be most beneficial — and most cost-effective in the long-term - is a program that provides a combination of child-direct, child-specific, and indirect services, with the intensity of each type of service being determined by individual need. Experts argue that truly effective ABA programs are comprised of multiple intervention methods used individually and dynamically to achieve the best outcomes (Steege et al., 2007). What may be most practical is to provide a "suite" of services that is tailored to the needs of each individual student and school. No one method of instruction is suited to all children with ASD. When interventions are 
matched to the unique characteristics of each student their effectiveness and efficiency are maximized (Grey et al., 2005). Crone and colleagues (Crone, Horner, \& Hawken, 2004) estimated that approximately $5 \%$ of students have problem behaviours serious enough to require intensive, individualized interventions. For those students with ASD with more complex needs, studentdirect instruction may be essential, while those with less complex needs may benefit more from full integration with consultant-trained educators using ABA and other evidence-based behavioural teaching strategies effectively in the classroom. Students with all kinds of needs would most certainly benefit from a supportive school environment, which this study suggests may be enhanced through the implementation of the various components of an indirect service delivery model.

On average, educators reported that all components of the SSP-ASD program were useful. Professional development day sessions and individual consultation and support - particularly with respect to collaboration and problem solving-were identified as aspects of services that were most useful. ASD consultants also felt professional development day sessions were useful and both educators and consultants agreed on the usefulness of observation of students in the classroom by consultants. Information received about accessing other services or community agencies was perceived to be least useful by both educators and ASD consultants. Broadening the program's scope to include more links to and greater involvement with community agencies is another area for program development.

Utilization of the SSP-ASD program might also be enhanced. Still, educators who reported working with more students with ASD were, for the most part, those who received more service (i.e., five or more contacts). This suggests that program resources were being used costeffectively as those who required services most used them more often. Information from this preliminary study will be useful for enhancement of services provided by the SSP-ASD program.

\section{Study Limitations and Directions for Future Research}

Due to the quasi-experimental study design, it cannot be concluded definitively that beneficial effects found by the study were due to services provided by the SSP-ASD program. It was to the advantage of the study that a naturally occurring comparison group was available. In addition, the use of ANCOVA allowed for the adjustment of possible pre-existing differences at baseline for pretest scores and number of students with ASD that educators worked with between the experimental and comparison groups. However, it is not possible to be completely confident that initial differences were controlled for entirely. Associated but unmeasured differences may have influenced study results.

Second, roughly $6 \%$ of educators randomly chosen for inclusion in the study declined to participate. Therefore, the study sample was not wholly representative of the specific population of interest. This raises concerns about external validity. Moreover, about 35\% of study participants completed the study pretest questionnaire only, raising concerns about internal validity. However, as study analyses indicated, those participants who completed the pretest questionnaire only did not differ significantly from those who completed both pretest and posttest questionnaires on pretest scores for study outcomes.

This preliminary study was conducted to evaluate whether the SSP-ASD program was having a positive impact on proximal level (educator level and school level) outcomes over the course of the second year of program implementation and to assess educators' satisfaction with the program. A future evaluation of the SSP-ASD program and evaluations of similar programs 
would benefit from the use of randomization of participants to conditions and more effective ways of increasing participation and minimizing non-response. It would also be beneficial to survey educators over a longer period of time. Additional data collection time points at 18, 24, and 36 months may identify differences in outcomes over time. This preliminary study suggests that aspects of the school environment can be modified by indirect services in a way that could potentially have a positive impact on outcomes for students with ASD. A longitudinal study would be of benefit to examine how components of the school support program modify various aspects of the school environment over time and how those modified aspects of the environment, in turn, may influence child outcomes.

It would also be beneficial for future evaluations of this and other school support programs to supplement educator reports with reports from school board staff, parents, and community service providers, as well as with more objective measures of program effectiveness, such as school records of behavioural problems. Additional sources of information would help to validate educator reports and allow researchers to make more informed judgments about program effectiveness. Future studies of this and other school support programs could examine changes to other aspects of the school environment not examined in the present study, such as peer support for students with ASD. Also, the findings of this preliminary study suggest that future research in this area would benefit from the development and testing of questionnaires specifically designed to measure the effectiveness of indirect services for building the capacity of educators and schools to meet the needs of students with ASD. Furthermore, it is essential for future research to compare the effectiveness and cost-effectiveness of different service delivery models (i.e., direct school-based interventions for children with ASD vs. services delivered according to an indirect model [such as the SSP-ASD program evaluated in the present study] vs. services that combine service delivery models) for enhancing both the school environment and child outcomes.

\section{References}

Baer, D., Wolf, M., \& Risely, T. (1968). Some current dimensions of applied behavior analysis. Journal of Applied Behavior Analysis, 1, 91-97.

Barnard, J., Prior, A., \& Potter, D. (2000). Inclusion and autism: Is it working? United Kingdom: The National Autistic Society.

Charman, T., Howlin, P., Berry, B., \& Prince, E. (2004). Measuring developmental progress of children with autism spectrum disorder on school entry using parent report. Autism, 8, 89-100.

Crone, A., Horner, R., \& Hawken, L. S. (2004). Responding to problem behavior in schools: The behavior education program. New York: Guilford Publications.

Eikeseth, S., Smith, T., Jahr, E., \& Eldevik, S. (2002). Intensive behavioral treatment at school for 4- to 7year-old children with autism: A 1-year comparison controlled study. Behavior Modification, 26, 49-68.

Fletcher-Campbell, F. (2003). Review of the research literature on the educational interventions for pupils with autism spectrum disorders. United Kingdom: National Foundation for Educational Research.

Games, P. (1990). Alternative analyses of repeated-measure designs by ANOVA and MANOVA. In A. von Eye (Ed.), Statistical methods in longitudinal research (pp. 81-121). Boston: Academic Press Inc.

Grey, L., Honan, R., McClean, B., \& Daly, M. (2005). Evaluating the effectiveness of teacher training in applied behavior analysis. Journal of Intellectual Disabilities, 9, 209-227. 
Harrison, J. (1998). Improving learning opportunities in mainstream secondary schools and colleges for students on the autism spectrum. British Journal of Special Education, 25, 179-183.

Herron, E., \& Buss, J. (1991). Project ACCESS: Providing support and technical assistance to rural schools serving students with Autism. Nashville, TN: Conference Proceeding, Rural Education Symposium. Eric Document No. 342578.

Hughes, J., Erchul, W., Yoon, J., Jackson, T., \& Henington, C. (1997). Consultant use of questions and its relationship to consultee evaluation of effectiveness. Journal of School Psychology, 35(1), 1-17.

Hughes, J., Hasbrouck, J., Serdahl, E., Heidgerken, A., \& McHaney, L. (2001). Responsive systems consultation: A preliminary evaluation of implementation and outcomes. Journal of Educational and Psychological Consultation, 12, 179-201.

Ikeda, M., Tucker, R., \& Rankin, B. (2002). Development, testing, and dissemination of nonaversive techniques for working with children with Autism: Demonstration of a "Best Practices" model for parents and teachers. The A-B-C-D model for supporting students with Autism (antecedents, behaviors, consequences, data). Washington, DC: Special Education Programs. Eric Document No. 472087.

Jackson, L. (2004). Emerging issues in Positive Behavior Support: Bringing school-wide support into alignment with person-centered support. In B. Bartlett \& F. Bryer (Eds.), Educating: Weaving research into practice (pp. 31-47). Nathan, Qld: Griffith University, School of Cognition, Language and Special Education.

Jacobson, J. (2000). Early intensive behavioral intervention: Emergence of a consumer-driven service model. The Behavior Analyst, 23, 149-171.

Jindal-Snape, D., Douglas, W., Topping, K., Kerr, C., \& Smith, E. (2005). Effective education for children with autistic spectrum disorder: Perceptions of parents and professionals. The International Journal of Special Education, 20, 77-87.

Joyce, B., \& Showers, B. (2002). Student achievement through staff development. Alexandria, VA: Association for Supervision and Curriculum Development.

LaRose, L., \& Perry, A. (2006). Child outcomes of intensive behavioural intervention (IBI) in the South West Region: A program evaluation report. London, ON: Thames Valley Children's Centre.

Larsen, D. L., Attkisson, C. C., Hargreaves, W. A., \& Nguyen, T. D. (1979). Assessment of client/patient satisfaction: Development of a general scale. Evaluation and Program Planning, 2, 197-207.

Lerman, D., Vorndran, C., Addison, L., \& Contrucci-Kuhn, S. (2004). Preparing teachers in evidencebased practices for young children with autism. School Psychology Review, 33, 510-526.

Lipsey, M. (1990). Design sensitivity: Statistical power for experimental research. Newbury Park, CA: Sage Publications, Inc.

Lovaas, O. (1987). Behavioral treatment and normal educational and intellectual functioning in young autistic children. Journal of Consulting and Clinical Psychology, 55, 3-9.

Luiselli, J., Putnam, R., Handler, M., \& Feinberg, A. (2005). Whole-school positive behaviour support: Effects on student discipline and academic performance. Educational Psychology, 23, 183-198.

Maurice, C., Green, G., \& Luce, S. (1996). Behavioral interventions for young children with autism. Austin, TX: Pro-Ed.

McClannahan, L., \& Krantz, P. (1994). The Princeton Child Development Institute. In S. Harris \& J. Handleman (Eds.), Preschool education programs for children with autism. Austin, TX: ProEd.

McEachin, J., Smith, T., \& Lovaas, O. (1993). Long-term outcome for children with autism who received early intensive behavioral treatment. American Journal on Mental Retardation, 97, 359-372.

Perry, A. (2006). Child outcomes of intensive behavioural intervention (IBI) in the Ontario Preschool Autism Program: A retrospective file review program evaluation report. Toronto, ON: York University.

Proactive Information Services, Inc. (1998). Profile: Factors for a supportive learning environment. Winnipeg, MB: Author. 
Rutter, M. (2005). Autism research: Lessons learned from the past and prospects for the future. Journal of Autism and Developmental Disorders, 35, 241-257.

Rutter, M., \& Maughan, B. (2002). School effectiveness findings: 1979-2002. Journal of School Psychology, 40, 451-475.

Sellström, E., \& Bremberg, S. (2006). Is there a "school effect" on pupil outcomes? A review of multilevel studies. Journal of Epidemiology and Community Health, 60, 149-155.

Simpson, R. (2005). Evidence-based practices and students with autism spectrum disorders. Focus on Autism and Other Developmental Disabilities, 20, 140-149.

Singleton, R., Straits, B., \& Straits, M. (1993). Approaches to social research (2nd ed.). New York: Oxford University Press.

Steege, M., Mace, C., Perry, L., \& Longenecker, H. (2007). Applied Behavior Analysis: Beyond discrete trial teaching. Psychology in the Schools, 44, 91-99.

\section{Author's Note}

Correspondence concerning this article should be addressed to Janette McDougall, Research Program, Thames Valley Children's Centre, 779 Base Line Road East, London, ON, Canada, N6C 5Y6. Email: janettem@tvcc.on.ca 